\title{
Application of FTIR and LA-ICPMS Spectroscopies as a Possible Approach for Biochemical Analyses of Different Rat Brain Regions
}

\author{
Mohamed H. M. Ali ${ }^{1, *}$, Fazle Rakib ${ }^{2} \oplus$, Volker Nischwitz ${ }^{3}$, Ehsan Ullah ${ }^{4}$, Raghvendra Mall ${ }^{4}($, \\ Amjad M. Shraim ${ }^{2}$, M. I. Ahmad ${ }^{5}$, Zafar Khan Ghouri ${ }^{6}{ }^{(1)}$, Donald McNaughton ${ }^{7}$, \\ Stephan Küppers ${ }^{3}$, , Tariq Ahmed ${ }^{1}\left(\right.$ and Khalid Al-Saad ${ }^{2}$ \\ 1 Qatar Biomedical Research Institute (QBRI), Hamad Bin Khalifa University (HBKU), Doha 34110, Qatar; \\ taahmed@qf.org.qa \\ 2 Department of Chemistry and Earth Sciences, Qatar University, Doha 2713, Qatar; fazle@qu.edu.qa (F.R.); \\ amjad@qu.edu.qa (A.M.S.); kalsaad@qu.edu.qa (K.A.-S.) \\ 3 Forschungszentrum Jülich $\mathrm{GmbH}$, Zentralinstitut für Engineering, 52425 Elektronik und Analytik, Germany; \\ v.nischwitz@fz-juelich.de (V.N.); s.kueppers@fz-juelich.de (S.K.) \\ 4 Qatar Computing Research Institute (QCRI), Hamad Bin Khalifa University, Doha 34110, Qatar; \\ eullah@hbku.edu.qa (E.U.); rmall@hbku.edu.qa (R.M.) \\ 5 Central Laboratories Unit, Qatar University, Doha 2713, Qatar; mohammad.ibrahim@qu.edu.qa \\ 6 Chemical Engineering Program, Texas A\&M University at Qatar, Doha 23874, Qatar; \\ zafarkhanghouri@hotmail.com \\ 7 Centre for Biospectroscopy and the School of Chemistry, Monash University, Clayton, Victoria 3800, \\ Australia; donald.mcnaughton@monash.edu \\ * Correspondence: mohamali@hbku.edu.qa
}

Received: 8 October 2018; Accepted: 19 November 2018; Published: 1 December 2018

\begin{abstract}
Fourier Transform Infrared Spectroscopy (FTIR) is a non-destructive analytical technique that has been employed in this research to characterize the biochemical make-up of various rat brain regions. The sensorimotor cortex, caudate putamen, thalamus, and the hippocampus were found to have higher olefinic content - an indicator of a higher degree of unsaturated fatty acids-rich in short-chain fatty acids, and low in ester and lipid contents. While the regions of the corpus callosum, internal, and external capsule were found to contain long-chained and higher-esterified saturated fatty acids. These molecular differences may reflect the roles of the specific regions in information processing and can provide a unique biochemical platform for future studies on the earlier detection of pathology development in the brain, as a consequence of disease or injury. Laser Ablation Inductively Coupled Plasma Mass Spectroscopy (LA-ICP-MS) is another vital analytical technique that was used in this work to analyze the elements' distribution patterns in various regions of the brain. The complementary data sets allowed the characterization of the brain regions, the chemical dominating groups, and the elemental composition. This set-up may be used for the investigation of changes in the brain caused by diseases and help create a deeper understanding of the interactions between the organic and elemental composition.
\end{abstract}

Keywords: FTIR imaging spectroscopy; biochemical analysis; brain; LA-ICP-MS

\section{Introduction}

The mammalian brain is sub-divided into numerous regions, each with a specific physiological function. Dissection down the midline identifies the two most visible features-an interior core of white matter (WM), composed of phospholipid rich myelinated axons, and an exterior layer of 
gray matter (GM), composed of arborized neurons with un-myelinated axons [1]. Due to the brain's complexity, there remains an important need for novel technologies that further delineate the (sub-) cellular components, in order to monitor and characterize the bio-chemical changes associated with neurological dysfunctions. The drawbacks of the current bio-diagnostic technologies are that they are too time-consuming, provide low resolution, and alter tissue integrity.

Current imaging techniques, such as positron emission tomography (PET), magnetic resonance imaging (MRI), and computerized tomography (CT), are used to identify disease pathology. CT imaging is rapid, highly reproducible and low in cost for clinical brain-injury screening. However, it is not equipped to detect all types of lesions in the brain, specifically, those related to the development of the secondary injury. MRI has long been the gold standard to study changes in gross brain morphology, and has been routinely used to examine the peri-infarct zone, following a stroke. Unfortunately, MRI does not have sufficient spatial resolution to study individual cells within the brain and reveals little information on the biochemical mechanisms of tissue insult [2].

Infrared (IR) spectra originate from the vibrational motions of atoms, in chemical bonds [3]. As the molecule absorbs the electromagnetic radiation, it produces a band in the IR spectrum, at specific frequencies [4]. The IR spectra vibrational frequencies provide information about chemical compounds, including bio-molecules, and produce characteristic fingerprint for proteins, lipids, cholesterols, phospholipids, carbohydrates, and nucleic acids, as well as providing a unique biochemical and biophysical fingerprint for the sample [5]. Fourier transform infrared (FTIR) spectroscopy is a simple, sensitive, accurate, highly-reproducible, non-destructive (with respect to sample preparation), and rapid, diagnostic technique [6]. In contrast to the standard histological staining methods, FTIR is the "state-of-the-art" bio-diagnostic and bio-imaging technology for fast diagnosis in medicine and biological studies. It has been used to screen and characterize a wide range of tissues and organs [7-9]. FTIR imaging spectroscopy has also been used to analyze the pathological changes associated with stroke, traumatic brain injury (TBI), and neurodegenerative diseases, such as Alzheimer's disease (AD), Parkinson's disease (PD), and multiple sclerosis (MS) [10-12]. We report here that FTIR technology is relatively straightforward and rapid. There is no requirement of prior treatment of brain samples with dyes, or reagents, in order to characterize the different brain structures, and the technique, in addition, is non-destructive, which allows the sample to be analyzed with additional techniques. Hence, FTIR can be a fast, reproducible technique, in order to characterize the biochemical make-up of various brain regions, to provide a good platform for investigating brain alterations at the molecular-level, such as in the cases of neurological disorders. Furthermore, a combined analysis of FTIR and Laser Ablation Inductively Coupled Plasma Mass Spectrometry (LA-ICP-MS) imaging can improve the brain tissue elemental characterization and classification, expediting the diagnostics and therapeutics. LA-ICP-MS has been shown to be a powerful technique for brain tissue imaging [13-17]. One disadvantage is that it is a destructive technique but, in combination with FTIR, the same sample can be analyzed to overlay the information of both techniques and can show changes, especially with respect to diseases, in the aging of brains. Specifically, the combination may be a tool to easily classify different diseases and may help to evaluate the biochemical impacts of different diseases.

\section{Materials and Methods}

\subsection{Sample Preparation}

All experimental protocols and animal handling procedures were approved by the University of Utrecht Animal Research Ethics Board. A total of 6 male (11-week-old Sprague-Dawley rats), were included in the study. The animals were sacrificed with an overdose of isofluorane, followed by transcardial perfusion. Then, the brains were extracted, embedded in paraffin, and the paraffin-embedded brain tissue blocks were serially cut into $10 \mu \mathrm{m}$ sections, using a microtome (Leica RM 2155 semi-automated rotary microtome, Nussloch, Germany). All samples were treated in an identical manner, during sample processing and preparation. The areas of interest consists of 
seven brain regions including the somatosensory motor cortex (SSMC), the corpus callosum (CC), the caudate putamen (CP), from the Bregma $1.56 \mathrm{~mm}$, and the external capsule (EC), the capsule interna (IC), the hippocampus (HC), and the thalamus (TH) from the Bregma $4.36 \mathrm{~mm}$. From each rat, five brain sections of similar anatomy were collected and twenty FTIR spectra were recorded from each brain region. Serial and consecutive sections were collected for the LA-ICP-MS and a routine hematoxylin and eosin (H\&E) staining analyses [2].

\subsection{Fourier Transform Infrared Spectroscopy (FTIR)}

FTIR spectra were recorded using the FTIR Cary 620 spectrometer in the reflection mode, within the range of $4000-700 \mathrm{~cm}^{-1}$, with 64 scans per spectrum and a $4 \mathrm{~cm}^{-1}$ spectral resolution. Background single beam spectra were measured on a substrate, without the biological tissue, by co-adding sixty-four scans. FTIR images were recorded using a $64 \times 64$ focal plane array instrument with Mercury Cadmium Telluride (MCT, California, USA), Agilent Technology. FTIR imaging was performed with an objective of $15 \times$ magnification and 0.62 numerical aperture, yielding a pixel size of $5.5 \times 5.5 \mu \mathrm{M}$.

\subsection{FTIR Data Processing and Analysis}

Spectra acquired from the border between a brain tissue and a substrate, affected by resonance Mie scattering (commonly present in biological samples) and spectra recorded from a substrate (outside the brain tissue area) were eliminated from further analysis [18]. FTIR spectra were vector normalized between $3500-900 \mathrm{~cm}^{-1}$ and the baseline correction was performed on the full range of wavelengths for the spectra. The relative amount of the specific molecular content was quantified from the original absorbance spectra [2]. The approximate values were determined from the brain samples of different animals, based on their bio-chemical variations. Functional group images were obtained by calculating the ratios of the baseline corrected areas, under some peaks, based on Table 1 (see Figure 1). The total lipid content was represented by the C-H stretching region at $2994-2800 \mathrm{~cm}^{-1}[19,20]$. The protein concentration was represented by the amide II band at 1555-1535 [21,22]. For more insight and deep lipid analysis, the ratios of some specific lipid spectral bands $\left(v_{\mathrm{as}}\left(\mathrm{CH}_{3}\right)\right.$ asymmetric, $\mathrm{v}_{\mathrm{s}}\left(\mathrm{CH}_{2}\right)$ symmetric, $v_{\text {as }}\left(\mathrm{CH}_{2}\right)$ asymmetric stretching, carbonyl ester $v(\mathrm{C}=\mathrm{O})$ ester, and olefinic $=\mathrm{CH}$ bands), to the total lipid ( $\mathrm{C}-\mathrm{H}$ stretching region), were calculated. For each animal, a mean and standard deviation was calculated and the average $(n=6)$ was generated. Mann Whitney-U test was performed on all data to test for significant differences $(p<0.05)$. All $t$-tests were two-tailed and the $95 \%$ confidence limit was used to test for significance.

Table 1. The spectral regions used for the analytical purposes.

\begin{tabular}{cc}
\hline Infrared Band & Spectral Rage $\mathbf{( c m}^{-\mathbf{1}} \mathbf{)}$ \\
\hline Lipid components & \\
$\mathrm{CH}_{2}$ symmetric stretching & $2852-2800$ \\
$\mathrm{CH}_{2}$ asymmetric stretching & $2915-2930$ \\
$\mathrm{CH}_{3}$ asymmetric stretching & $2950-2960$ \\
$*$ C-H stretching & $2994-2800$ \\
Olefin=CH & $3000-3027$ \\
Carbonyl ester $(\mathrm{C}=\mathrm{O})$ stretching & $1745-1731$ \\
Protein components & $1700-1600$ \\
Amide I & $1555-1535$ \\
Amide II &
\end{tabular}

Principal component analyses (PCA) were performed using "prcomp" function in the "stats" package in R. The PCA analysis was performed on the spectral second derivatives, in the range of $4000-700 \mathrm{~cm}^{-1}$ (the range of $2500-2000 \mathrm{~cm}^{-1}$ removed). PCA analysis was performed on a total of 
1270 wavenumbers, in the range of $4000-700 \mathrm{~cm}^{-1}$, from the FTIR spectra obtained from the different brain regions, and PCA was performed, based on the covariance of these features. Furthermore, during PCA we randomly divided the spectral collection into $80 \%$ training and $20 \%$ test. The norm of the reconstruction error for each test spectra was 0.05 , on average, while using the first three principal components. The 3D scores plot of these components enabled the spectra to be grouped according to the chemical information they contained. Hierarchical cluster analysis (HCA) was applied, using the "A2Rplot", to compare the seven brain regions, based on their PCA projections in the 3D score plot. HCA was used to group spectra that displayed the same degree of similarity. The result was visualized in a dendrogram and the grouping of the seven brain regions were presented in clusters, according to a heterogeneity scale $[23,24]$.
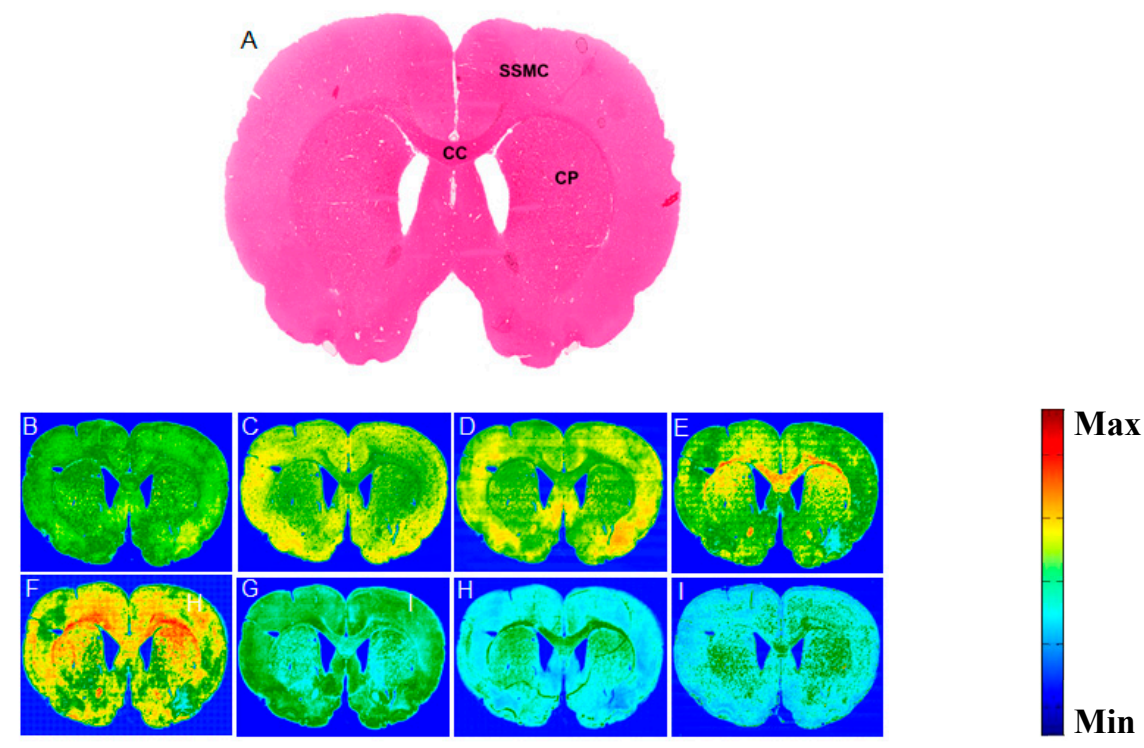

Figure 1. (A) H\&E staining section of the rostral brain (Bregma $1.56 \mathrm{~mm}$ ) showing the three regions of interest (ROI): SSMC, CC, and CP. (B) Corresponding FTIR image. (C-I) Representative images of the biochemical components-Amide I, Amide II, $\mathrm{CH}_{3}$ asymmetric, $\mathrm{CH}_{2}$ symmetric, $\mathrm{CH}_{2}$ asymmetric, Olefin, and Ester, accordingly. The color bar represents a high concentration, in red, and low concentration, in blue.

\subsection{Laser Ablation-ICP-MS}

An Inductively Coupled Plasma Quadrupole Mass Spectroscopy ICP-QMS (Agilent 7900, Agilent Technologies, Hachioji, Japan) was coupled to a laser ablation system NWR 213 (New Wave Research, CA, USA) for the elemental imaging. The laser spot size was $60 \mu \mathrm{m}$ with $30 \mu \mathrm{m}$ between the lines, at a laser energy of about $29 \%$. One measurement of each tissue sample was performed, with a scan speed of $70 \mu \mathrm{m} \mathrm{s}{ }^{-1}$. The isotopes ${ }^{13} \mathrm{C},{ }^{31} \mathrm{P},{ }^{34} \mathrm{~S},{ }^{43} \mathrm{Ca},{ }^{44} \mathrm{Ca},{ }^{54} \mathrm{Fe},{ }^{56} \mathrm{Fe},{ }^{57} \mathrm{Fe},{ }^{63} \mathrm{Cu},{ }^{65} \mathrm{Cu},{ }^{64} \mathrm{Zn},{ }^{66} \mathrm{Zn},{ }^{206} \mathrm{~Pb},{ }^{207} \mathrm{~Pb}$, and ${ }^{208} \mathrm{~Pb}$ were monitored; in case of multiple available isotopes the most abundant was evaluated and the results were cross-checked with the additional isotopes of the same element, to check for possibly occurring spectral interferences. Quantification of the $\mathrm{Fe}, \mathrm{Cu}, \mathrm{Zn}$, and $\mathrm{Pb}$ was performed, based on the rat brain-tissue standards. Blanks and five standards were prepared by spiking the homogenized rat brain tissue with elemental standard solutions. The resulting tissue, with the known concentrations (determined by the total elemental analysis), was frozen, cut in slices, and analyzed, in analogy to the samples. The calibration ranged from the blank tissue levels up to $19.8 \mathrm{mg} / \mathrm{kg}$ for Fe, up to $20 \mathrm{mg} / \mathrm{kg}$ for $\mathrm{Cu}$, up to $30 \mathrm{mg} / \mathrm{kg}$ for $\mathrm{Zn}$, and up to $2.5 \mathrm{mg} / \mathrm{kg}$ for $\mathrm{Pb}$. The relative intensities of $\mathrm{C}, \mathrm{P}, \mathrm{S}$, and $\mathrm{Ca}$, were seen due to the lack of calibration standards. Image reconstruction was performed by a software developed in-house (Forschungszentrum Jülich), giving the scale in $\mathrm{mg} / \mathrm{kg}$, for the elements with calibration. Due to the complex process of ablating and transferring the aerosol into the ICP-MS, 
there are several sources of uncertainty. Therefore in this work, the main focus was on identifying the elemental patterns within the tissue sections but not on an exact quantification.

\section{Results}

The formalin-fixed paraffin-embedded brain tissue samples (serial sections of $10 \mu \mathrm{m}$ thickness), were collected from each rat for the FTIR, LA-ICP-MS, and the H\&E analyses. The numerical comparisons of the lipid/protein ratio and the ratios of some specific lipid spectral of the regions of interest of this study, are listed in Table 1. Figure 1A shows a rostral section (Bregma 1.56), highlighting three other regions of interest-SSMC, CC, and CP; the corresponding FTIR image is shown in Figure 1B. Figure 1C-I shows the images of the biochemical components-Amide I, Amide II, $v_{\text {as }}\left(\mathrm{CH}_{3}\right)$ asymmetric, $v_{\mathrm{s}}\left(\mathrm{CH}_{2}\right)$ symmetric, $v_{\text {as }}\left(\mathrm{CH}_{2}\right)$ asymmetric stretching, olefin, and ester, respectively. These images were colored, according to the calculated biochemical content values, where red color corresponded to the highest bio-content and the blue color corresponded to the lowest bio-content, as shown on the color bars in the figure. The FTIR spectra of the SSMS, CC, and CP are shown in Figure 2A-C, respectively. Figure 2A represents the SSMC average FTIR spectrum. The spectrum revealed the ester absorption band that arose at $\sim 1730 \mathrm{~cm}^{-1}$ from the $v(C=O)$ ester (carbonyl) group, had weak absorption. The FTIR spectrum revealed that a robust olefinic $=\mathrm{CH}$ band arose at about $3012 \mathrm{~cm}^{-1}$. This was interpreted as that the SSMC structure contains lipids with a high degree of unsaturation. The protein absorption bands, such as amide II, amide I, and the N-H bands, arose at 1545, 1653, and $3290 \mathrm{~cm}^{-1}$, respectively. The amide I and amide II have strong absorption.
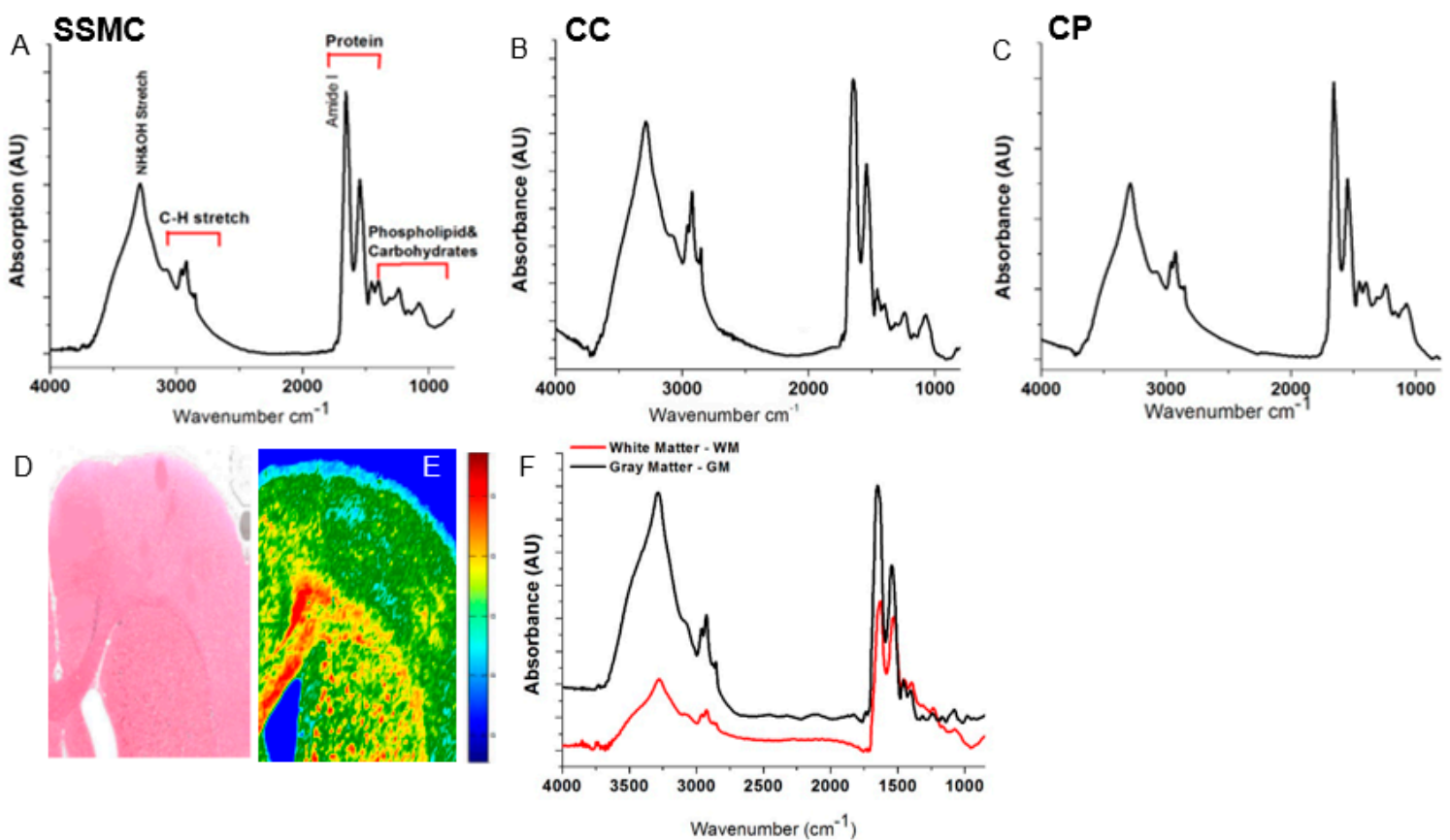

Figure 2. (A-C) Representative FTIR spectra of the SSMC, CC, and CP. (D) H\&E images of the WM and the GM, and (E) FTIR image of the same region with a high-resolution, based on the lipid/protein ratio. (F) FTIR spectra of the WM and the GM. The color bar represents a high-concentration, in red, and a low-concentration, in blue.

The spectral data collected from the CC, in Figure 2B, revealed a strong peak which ascended from the $v(\mathrm{C}=\mathrm{O})$ at $1470 \mathrm{~cm}^{-1}$, which was attributed to the phospholipid. The FTIR spectrum revealed that the olefinic $=\mathrm{CH}$ band was weaker in the $\mathrm{CC}$, than in the SSMC. Whereas, the FTIR spectrum identified that the band at $1464 \mathrm{~cm}^{-1}$, which arose from the $\mathrm{CH}_{2}$ bending vibration, was robust. The bands at 2852 and $2955 \mathrm{~cm}^{-1}$ that arose from the $v_{\mathrm{s}}\left(\mathrm{CH}_{2}\right)$ and $v_{\mathrm{as}}\left(\mathrm{CH}_{2}\right)$, showed stronger absorption than 
the SSMC spectrum. The band at $2955 \mathrm{~cm}^{-1}$ which arose from the $v_{\text {as }}\left(\mathrm{CH}_{3}\right)$ of the lipids fatty acids, showed weaker absorption, in comparison to the SSMC spectrum.

Figure $2 \mathrm{C}$ is a representative FTIR spectrum of the $\mathrm{CP}$. Here, the spectral band of the carbonyl group $v(\mathrm{C}=\mathrm{O})$ of the ester component, had a low-absorption intensity, due to the low esterified-phospholipid content. The $v_{\mathrm{s}}\left(\mathrm{CH}_{2}\right)$ and $v_{\text {as }}\left(\mathrm{CH}_{2}\right)$ spectral bands showed a weaker absorption, in comparison to the CC spectrum. The FTIR spectrum at the $\mathrm{CP}$ region exhibited strong olefinic $=\mathrm{CH}$ band, in comparison to the $\mathrm{CC}$ spectrum; indicating that the $\mathrm{CP}$ was rich in unsaturated lipids The FTIR spectrum was dominated by amide I and amide II spectral bands.

Figure 2D is a representative H\&E image of the WM and GM, with the corresponding FTIR image obtained with a higher resolution, based on the lipid/protein ratio presented in Figure 2E. The data revealed here, that the white matter showed a higher intensity in the lipid/protein ratio signals, which correlated well with the presence of the myelin sheaths around the nerve axons located in this region. The spectra collected from these regions were dominated by the protein, lipid, and the ester bands (Figure 2F). The WM spectrum had two strong absorption bands, at 2850 and $2920 \mathrm{~cm}^{-1}$, compared to the spectrum collected from the gray matter. These bands arose from the $\mathrm{C}-\mathrm{H}$ stretching vibrations of the $v_{\mathrm{s}}\left(\mathrm{CH}_{2}\right)$ and $v_{\mathrm{as}}\left(\mathrm{CH}_{2}\right)$, respectively, from the fatty-acid content. We found from these results that there was a slightly stronger absorption in the ester region $v(C=O)$, at $1740 \mathrm{~cm}^{-1}$, for the $\mathrm{WM}$, confirming that the WM is lipid rich.

Figure $3 \mathrm{~A}$ is an example of the $\mathrm{H} \& \mathrm{E}$ image of a caudal brain section that represented three regions of interest: $\mathrm{HC}, \mathrm{TH}$, and EC. Figure 3B shows the corresponding FTIR image from these sub-fields. Figure $3 \mathrm{C}-\mathrm{I}$ represent the biochemical components of this caudal brain section. The hippocampus H\&E stain (Figure 4A), clearly shows the cyto-architecture of this organ. The figure revealed that the hippocampus has densely-packed neurons in the cornu ammonis (CA) sub-fields and the dentate gyrus (DG), and a smooth, less-dense upper region of the avleus (AV). The spectroscopic results (Figure 4B) indicate that there is a similarity between the CA and DG spectra, in contrast with the AV spectrum. The main differences were observed in the following spectral bands: (a) In the AV's FTIR spectrum, the intensity of the $v_{\mathrm{s}}\left(\mathrm{CH}_{2}\right), v_{\text {as }}\left(\mathrm{CH}_{2}\right)$, and the $v(\mathrm{C}=\mathrm{O})$ ester bands showed stronger absorption than the CA and DG spectra, indicating that the AV is enriched in lipid content. (b) The olefinic structure olefinic $=\mathrm{CH}$ band at 3012 was stronger in the $\mathrm{CA}$ and DG spectra than the AV spectrum. (c) The band at $2955 \mathrm{~cm}^{-1}$ which arose from the $v_{\mathrm{as}}\left(\mathrm{CH}_{3}\right)$, was stronger in the $\mathrm{CA}$ and the dentate gyrus (DG) spectra than the AV spectrum. (d) The amide I and amid II bands exhibited a higher absorption in the in the CA and the DG spectra, in comparison to the AV spectrum. (e) The spectra revealed that the CA and DG regions yielded a low lipid-intensity, while the $\mathrm{CH}_{2}$ spectral bands had a strong absorption, at the white matter location, which surrounded the entire hippocampus. These intense $\mathrm{CH}_{2}$ bands were due to the high lipid-bilayer concentration in the white matter.

The averaged spectral data, collected from the TH region (Figure 4C), revealed that the spectral bands of the $v_{\mathrm{s}}\left(\mathrm{CH}_{2}\right), v_{\mathrm{as}}\left(\mathrm{CH}_{2}\right)$, and $v(\mathrm{C}=\mathrm{O})$ ester, showed weaker absorptions; indicating that the esterified-phospholipid, in the TH, was low. The TH's FTIR spectrum exhibited strong amide I and amide II absorption bands. The FTIR spectrum revealed a high absorption in the spectral band around $3012 \mathrm{~cm}^{-1}$, which arose from the olefinic $=\mathrm{CH}$ structure. These results indicated that the TH bio-chemical make-up contains lipids with a high degree of unsaturation. The FTIR spectrum of the $\mathrm{TH}$ yielded strong $v_{\mathrm{as}}\left(\mathrm{CH}_{3}\right)$ bands at $2955 \mathrm{~cm}^{-1}$, which arose from the lipid structure, and a $\mathrm{PO}_{4}{ }^{2-}$ band at $1240 \mathrm{~cm}^{-1}$, which arose from the stretching vibrations of the nucleic acids.

The CE averaged spectrum (Figure 4D) identified that the $v_{s}\left(\mathrm{CH}_{2}\right)$ and $v_{\mathrm{as}}\left(\mathrm{CH}_{2}\right)$ bands of the lipid content of the $\mathrm{CE}$, showed a high absorption, due to the high lipid-content. The $\mathrm{CE}$ spectrum showed a high absorption peak at $1740 \mathrm{~cm}^{-1}$ that arose from the $v(\mathrm{C}=\mathrm{O})$ ester band of the lipid structure. This $\vee(\mathrm{C}=\mathrm{O})$ band was found to be weaker in the $\mathrm{CP}$ region. These results indicated that the $\mathrm{CP}$ contains less lipid contents than the CE (see Tables 2 and 3). The spectrum revealed that the amide I and amide II bands had a high absorption. The FTIR spectrum for the capsule interna (IC) region had a large similarity between the FTIR spectrums collected from the capsule externa (data not shown). 

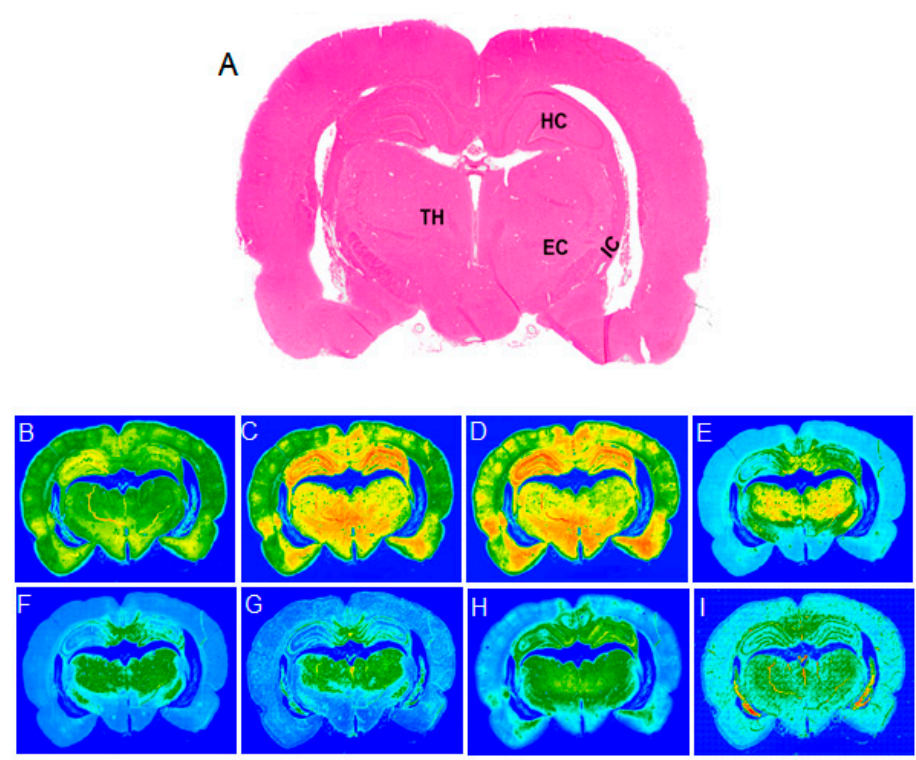

Max

Min

Figure 3. (A) H\&E staining section of the caudal brain (Bregma $-4.36 \mathrm{~mm}$ ) showing four regions of interest (ROI): HC, TH, IC, and EC. (B) Corresponding FTIR image. (C-I) Representative images of the biochemical components-Amide I, Amide II, $\mathrm{CH}_{3}$ asymmetric, $\mathrm{CH}_{2}$ symmetric, $\mathrm{CH}_{2}$ asymmetric, Olefin, and Ester, respectively.

A

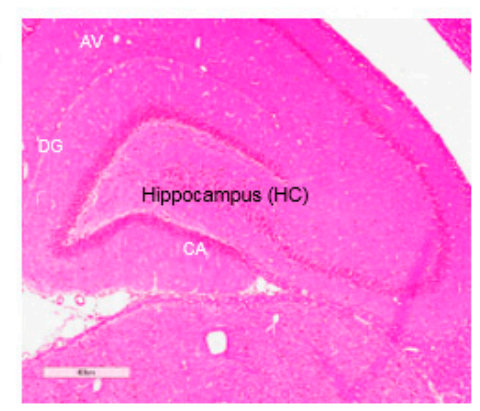

C $\mathrm{TH}$

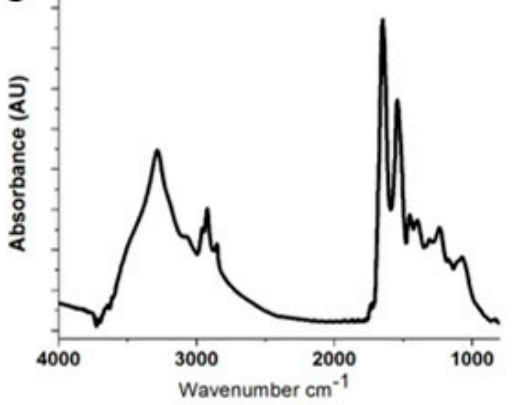

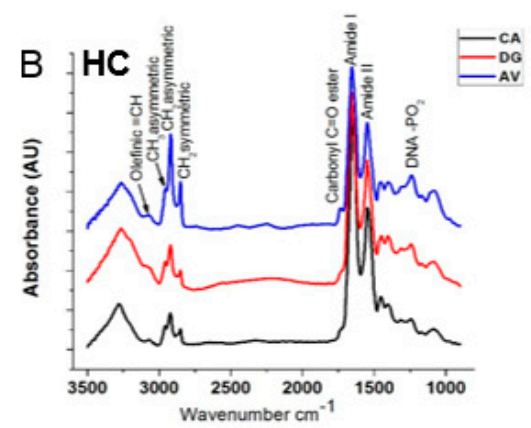

D. CE

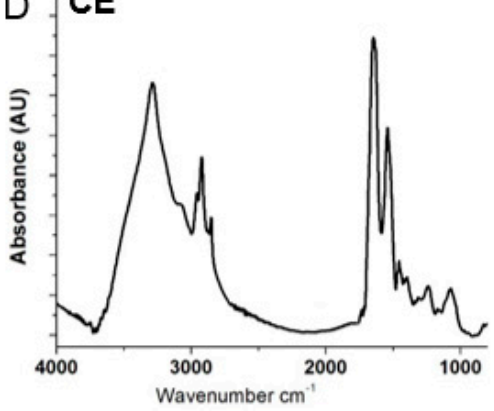

Figure 4. (A) H\&E image of the Hippocampus showing AV, DG, and CA. (B) FTIR spectra of these three regions. (C,D) Representative FTIR spectra of TH and CE, respectively. 
Table 2. Differences in the band-area ratios of various functional groups, within the regions of interest (ROI), of a control healthy rat brain sections.

\begin{tabular}{ccccccc}
\hline Ratio & SSMC & CC & CP & HP (CA) & TH & CE \\
\hline Lipid/Protein & $3.453 \pm 0.170^{*}$ & $6.902 \pm 0.204$ & $3.143 \pm 0.162$ & $2.984 \pm 0.144$ & $3.251 \pm 0.152 *$ & $5.893 \pm 0.215$ \\
CH $/$ lipid & $0.2283 \pm 0.0019^{*}$ & $0.3213 \pm 0.0028$ & $0.2243 \pm 0.0011 *$ & $0.2015 \pm 0.0012$ & $0.2146 \pm 0.0015^{*}$ & $0.2932 \pm 0.0024$ \\
Carbonyl ester/lipid & $0.0304 \pm 0.0012$ & $0.0382 \pm 0.008$ & $0.0291 \pm 0.0010$ & $0.0271 \pm 0.0008$ & $0.0264 \pm 0.0014$ & $0.0312 \pm 0.0013$ \\
Olefinic=CH/lipid & $0.0045 \pm 0.0004$ & $0.0028 \pm 0.0002 *$ & $0.0043 \pm 0.0003$ & $0.0041 \pm 0.0005$ & $0.0044 \pm 0.0010$ & $0.0023 \pm 0.0006 *$ \\
CH $_{3} /$ lipid & $0.0741 \pm 0.009$ & $0.0582 \pm 0.0007$ & $0.0736 \pm 0.013$ & $0.0693 \pm 0.008$ & $0.0713 \pm 0.007$ & $0.0541 \pm 0.0009$ \\
\hline
\end{tabular}

All the values are represented by the 'mean $\pm \mathrm{SD}^{\prime}$ for each region of interest, since $n=6$ and ${ }^{*} p<0.05$.

Table 3. Identification and differentiation of the regions of interest (ROI), within the brain sections.

\begin{tabular}{|c|c|c|c|c|c|}
\hline \multirow{2}{*}{$\begin{array}{l}\text { Characteristic } \\
\text { Regions }\end{array}$} & \multirow{2}{*}{$\begin{array}{l}\text { Protein Region (Amide } \\
\text { I, Amide II) at } \\
1800-1480 \mathrm{~cm}^{-1}\end{array}$} & \multicolumn{2}{|c|}{ Lipid Region (C-H) Stretching $2994-2800 \mathrm{~cm}^{-1}$} & \multirow{2}{*}{$\begin{array}{l}v(C=O) \text { Carbonyl } \\
\text { Ester at } 1740 \mathrm{~cm}^{-1}\end{array}$} & \multirow{2}{*}{$\begin{array}{c}\text { Olefinic }=\mathrm{CH} \text { at } \\
3012 \mathrm{~cm}^{-1}\end{array}$} \\
\hline & & $\begin{array}{c}v_{\mathrm{s}}\left(\mathrm{CH}_{2}\right) \text { symmetric at } 2852 \\
\text { and } v_{\mathrm{as}}\left(\mathrm{CH}_{2}\right) \text { asymmetric at } \\
2922 \mathrm{~cm}^{-1}\end{array}$ & $\begin{array}{l}\operatorname{vas}(\mathrm{CH} 3) \\
\text { asymmetric at } \\
2955 \mathrm{~cm}^{-1}\end{array}$ & & \\
\hline SSMC & Strong & Moderate & Moderate & Weak & Moderate \\
\hline HC (CA) & Strong & Moderate & Moderate & Weak & Weak \\
\hline TH & Strong & Moderate & Moderate & Moderate & Moderate \\
\hline EC & Strong & Strong & Weak & Moderate & Weak \\
\hline
\end{tabular}

Presented in Figure 5A, is a 3D image of the score plot of the PCA analysis for the seven brain regions, based on the spectral second derivatives, in the range of $4000-700 \mathrm{~cm}^{-1}$ (the range of 2500-2000 $\mathrm{cm}^{-1}$ removed). The score plot revealed the three main principal components that separate the seven brain regions and are accounted for by PC1 (90\%), PC2 (2\%), and PC3 (2\%). These components form the PCA were based on the spectral variations between the FTIR spectra collected from each brain region. These variations were mainly located in the lipid, protein, ester structure, and the nucleic acids bio-contents. The dendrogram (Figure 5B) revealed that the spectral data were clustered into two major groups. The first two groups were sub-clustered under one main group, which was separated from the third group. The results indicated that the hippocampus structure was relatively close to the cortex, in the bio-chemical make-up, which indicated that the HC is a component part of the brain cortex, as evidenced by development studies-both are ectodermally-derived in the neural tube, during embryogenesis [25]. The results also indicated that the TH and $\mathrm{CP}$ are closely-related, due to the grey matter content. The IC, CE, and the CC are mainly related, due to the high content of the lipid axonal structure in the myelin sheaths of the white matter.

A

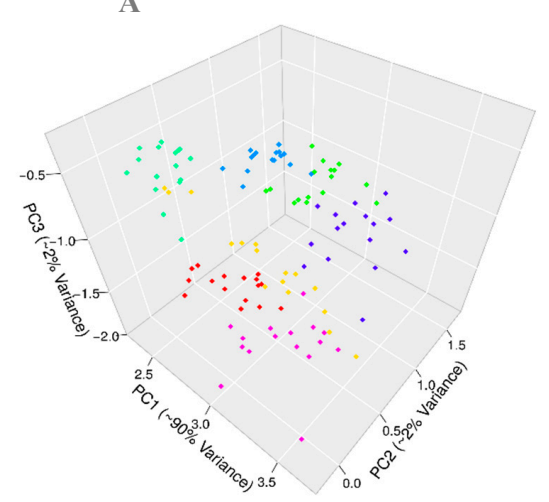

B

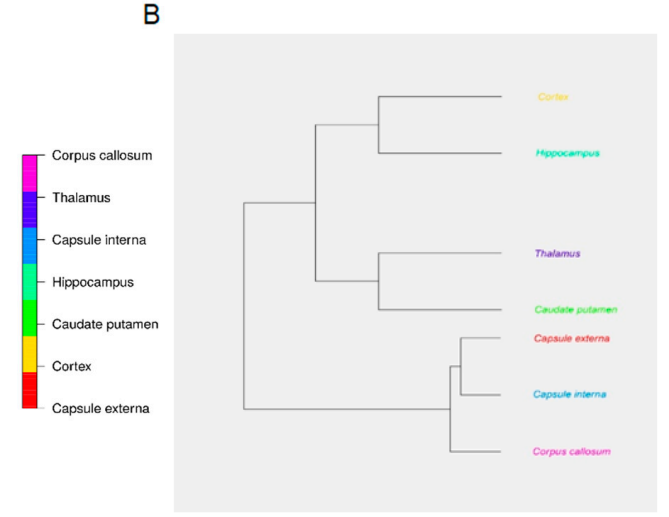

Figure 5. (A) PCA score plot for the seven brain regions. The three PCA values are given by PC1 (90\%), PC2 (2\%), and PC3 (2\%). (B) Dendrogram representing the seven brain regions. 


\subsection{Elemental analysis by Laser ablation (LA-ICP-MS)}

LA-ICP-MS was used to assess the distributions of the important elements, in the rat brain sections, such as $\mathrm{C}, \mathrm{Fe}, \mathrm{P}, \mathrm{S}, \mathrm{Cu}$, and $\mathrm{Zn}$ (Figure 6). From the rostral brain sections (Bregma 1.56), we detected high levels of $\mathrm{C}$ in the SSMC and in the CC (Figure 6). What was notable here was the high intensities of $\mathrm{Ca}, \mathrm{Mg}$, and $\mathrm{Cu}$ in the $\mathrm{WM}$, and in particular in the CC. Two other elements, Fe and $\mathrm{Zn}$, were evenly-distributed in the cortices and the basal ganglia, the former element was found to be enriched in the substantia nigra pars compacta-an area rich in dopamine neurons. Additionally, for the WM region, C, P, and S were also high in intensity—an indicator of high cell metabolism.

A

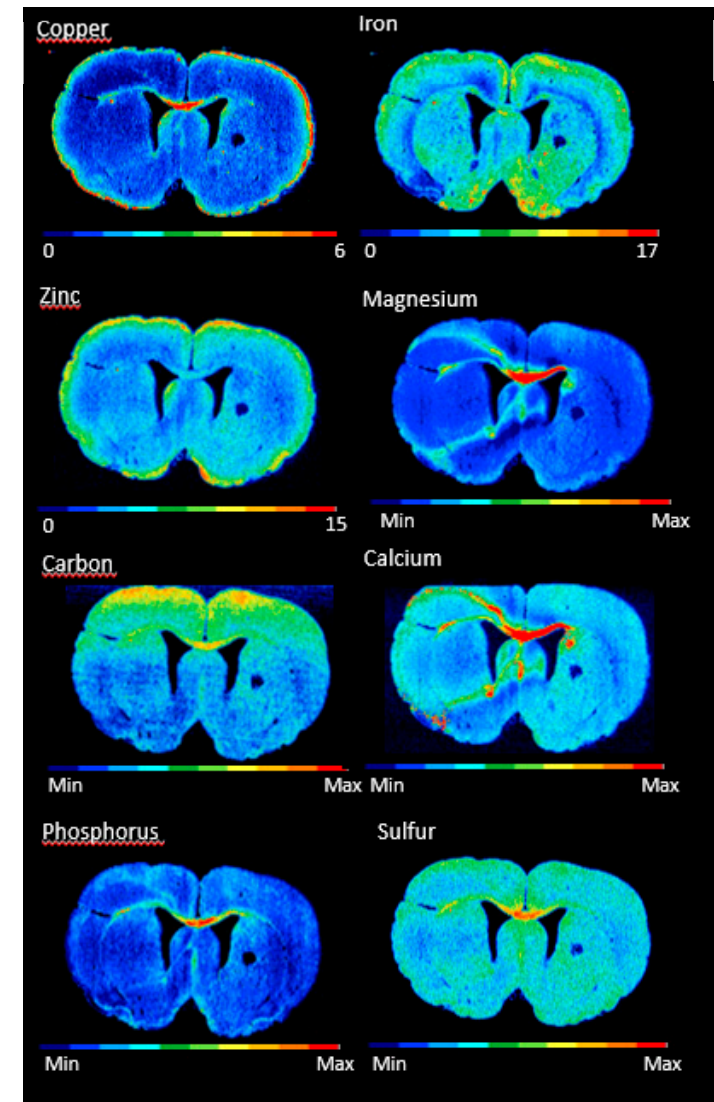

B
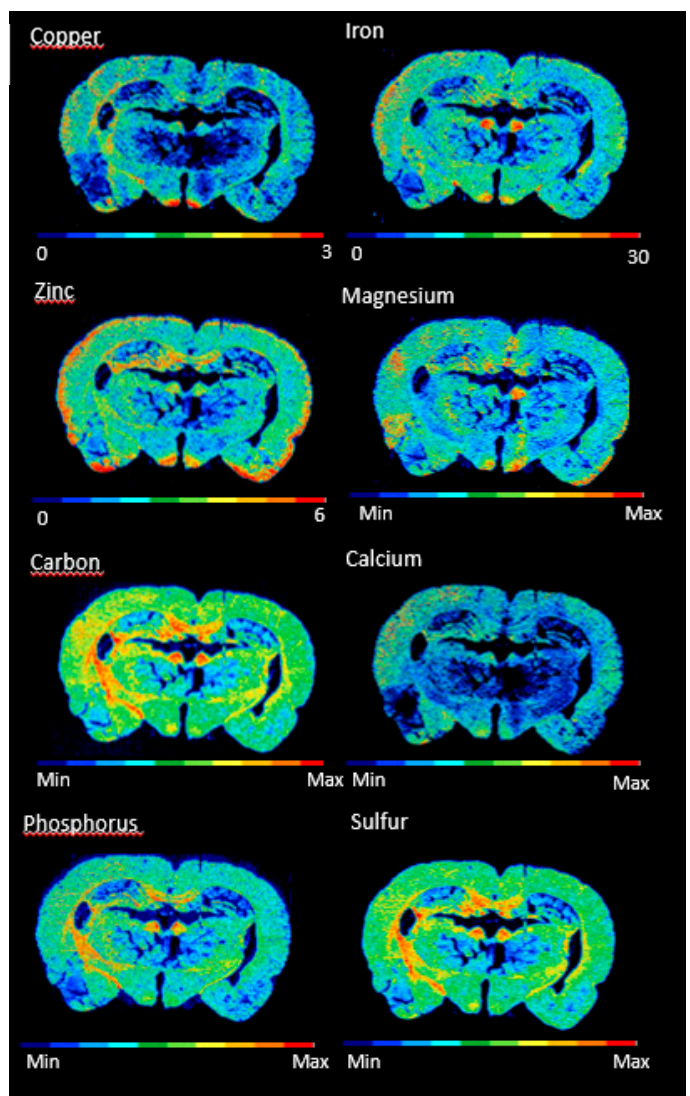

Figure 6. Distribution of the elements: (A) $\mathrm{Cu}, \mathrm{Fe}, \mathrm{Zn}, \mathrm{Mg}, \mathrm{C}, \mathrm{Ca}, \mathrm{P}$, and $\mathrm{S}$ in the rostral, and (B) the caudal part of rat brain sections. The color bar represents a high-concentration, in red, and a low-concentration, in blue.

For the Caudal brain sections (Bregma -4.36), C was homogenously-distributed across the brain sections, with a high signal in the WM, the $\mathrm{CC}$, and the Habenula. The divalent cations $\mathrm{Ca}, \mathrm{Mg}, \mathrm{Cu}$, $\mathrm{Fe}$, and $\mathrm{Zn}$ were fairly evenly-distributed, across the sections. As expected, Fe was also detected in the Habenula, the basal ganglia, and in the areas associated with the substantia nigra pars compacta. It should also be noted that the $\mathrm{Mg}, \mathrm{Cu}$, and $\mathrm{Zn}$ overlapped at specific regions and these hotspots were at brain sites closely-associated with active synaptic transmission. For the two inorganic elements, $\mathrm{P}$ and $\mathrm{S}$, we detected a high intensity in the WM and the CC (Figure 6). Whereas, $\mathrm{P}$ and $\mathrm{S}$ are components of the nucleic acids, ATP, phospholipids, and proteins, which are all possible indicators of a high metabolism/turnover, in these regions.

\section{Discussion}

In this study the bio-chemical composition of seven different brain regions from healthy rats were investigated, using FTIR and LAICPMS spectroscopies. Application of these techniques to 
mammalian tissue, is not new, but in comparison with standard histopathological techniques, these approaches offer much more biochemical detail that may be important and pertinent to advance the understanding of pathologies. In combination with the PCA data, other brain regions that may prove to be susceptible to diseases, may be identified. The study revealed that FTIR spectroscopy allows for the investigation of molecular structures from biological samples, with minimal sample preparation; providing a unique information that cannot be gained by alternate methods. Importantly, the technique is a non-destructive, sensitive, and fast, bio-diagnostic tool [26].

FTIR results were in alignment with published work that the gray matter is made up of neural cell bodies, astro-glials, and capillaries, and contains very little lipid [27]. This data also revealed that the WM consists mostly of myelinated axons, with a high lipid-content, which showed strong absorption bands in the lipid region $\left(3000-2750 \mathrm{~cm}^{-1}\right)$ and the ester band $\left(1740 \mathrm{~cm}^{-1}\right)$.

In order to get a more detailed understanding of the lipid-structure configuration in the brain, the ratio between certain lipid spectral bands to the total lipid contents, were measured. This may be a good indicator and platform for detecting tissue alterations associated with pathologies. The lipid/protein ratios reveals information about the cell membrane function, since the changes in the lipid-protein content can affect the membrane symmetry and thickness, and leads to the confirmation of changes in the membrane receptors and ion-exchange channels [28]. For example, the ratio between the $\mathrm{CH}_{2}$ spectral bands to the $\mathrm{C}-\mathrm{H}$ stretching of the total lipid band revealed information about the lipids chain length. The ratio between the olefinic $=\mathrm{CH}$ band at $3000-3027 \mathrm{~cm}^{-1}$ to the total lipid content at 2994-2800 $\mathrm{cm}^{-1}$, provided information on the degree of unsaturation in the lipid biological system [29]. The changes of the band ratios of certain bio-chemical component can be used for characterization purposes, as well as to monitor tissue alterations.

The high $\mathrm{CH}_{2}$ /lipid and low $\mathrm{CH}_{3}$ /lipid ratios in the $\mathrm{WM}, \mathrm{CC}$, and $\mathrm{CE}$ indicated that these regions are characterized by long fatty-acid chains. These results are in a good agreement with a previous report [30], which stated that brain WM contains long-chained fatty acids. In another study, the authors showed that the sphingolipids from gray matter contained predominantly medium-chained fatty acids, while those from myelin or from white matter, contained predominantly long-chained fatty acids [31]. These regions also showed a high ratio of $(\mathrm{C}=\mathrm{O})$ carbonyl ester/lipid, indicating a high content of esterified-fatty acids. In contrast, the regions of SSMC, CP, TH, and the CA and DG of the hippocampus, exhibited low $\mathrm{CH}_{2}$ /lipid and high $\mathrm{CH}_{3}$ /lipid ratios, indicating short fatty-acid chains. These differences may reflect the functions of these regions. The low Olefinic $=\mathrm{CH} /$ lipid ratio in the WM, CC, and CE, in comparison to the GM regions of SSMC, CP, TH, and the CA and DG of the hippocampus, indicated that these $\mathrm{WM}, \mathrm{CC}$, and $\mathrm{CE}$, were characterized by saturated and /or mono-saturated fatty acids, while the SSMC, $\mathrm{CP}, \mathrm{TH}$, and $\mathrm{HP}$ were predominantly characterized by polyunsaturated fatty acids. These results are in good agreement with the published data from Bazinet et al. [30]. The FTIR results revealed that in the HP, the CA and DG showed a lower lipid-content than in the AV region. The LA-ICP-MS chemical maps of carbon, phosphorus, and sulfur ions demonstrated a partial elevation of the concentration of those elements in the WM, which is a well-known difference between the WM and the GM, which is based on the abundant myelin in the $\mathrm{WM}$, in comparison to the GM [32]. The MS chemical images related to the $\mathrm{P}, \mathrm{C}$, and S, provide a distinct contrast between the WM and the neighboring tissue types. $\mathrm{Ca}, \mathrm{Cu}$, and $\mathrm{Fe}$ play an important role in regulating brain excitability and neuronal plasticity, through their action in neurotransmission, or function as second messengers [33]. These metal ions are bound up in metal-protein complexes or metalloproteins, such as enzymes, transport, and storage proteins, in which metals ion are critical for proper protein folding, structural stability, or enzymatic catalysis [34]. Therefore, they have a central role in many biochemical pathways that are explained by the elevated distribution of these elements in specific brain regions [34]. For example, the higher level of the iron ions in the substantia nigra is due to the dopaminergic metabolism within these neurons. Thus, the LA-ICP-MS data complement the FTIR data by providing an extra insight into the total brain composition and a clue about the functions. 
The chemometric analyses, such as principle component analysis and hierarchy dendrogram, showed that the seven regions of the brain were well-characterized and distinct, according to their spectral data. The score plot of the PCA delineated a clear separation between the brain regions, according to their lipid, ester, and protein content. Interpreting the dendrogram analyses we can argue that the hippocampus could be considered to be a distant part of the cerebral cortex. It was also concluded that all the regions that have a high-content of WM are clustered together, based on their lipid bio-chemical make-up. The eigenvalues graph showed that the control brain regions could be separated, based on the first three principal components, which accounted for more than $95 \%$ of the total variance in the spectral data. These variations were mainly located in the lipid, ester, and the protein spectral regions.

\section{Conclusions}

The FTIR spectroscopy is a good platform to reveal, examine, and investigate bio-chemical alterations associated with functional disorders in brain tissue. This makes the FTIR spectroscopy a valuable tool that can play an important role in the early detection of bio-chemical changes, at a sub-cellular level of neurological disorders, which would normally only be diagnosed when the pathology is at its most severe. The LA-ICP-MS elemental distribution maps provided information about what role and function these elements have in a particular brain region. This study showed that the FTIR and LA-ICP-MS techniques are powerful approaches to characterize the biochemical and elemental contents of brain tissue, providing complementary information to assess brain function. These techniques have been shown to be promising for tissue characterizations, as they offer unique opportunities for molecular and elemental assessments, for medical diagnoses.

Author Contributions: M.H.M.A. and F.R. performed all the FTIR and H\&E measurements in this study. M.A., T.A., A.S., and K.A.-S. were involved in the data interpretation and in drafting the manuscript. V.N. and S.K. was involved in the elemental measurements and analysis studies. R.M. and E.U. were involved in processing the experimental data and performing the multivariate and statistical analysis. All authors discussed the results and commented on the manuscript and on the critical revisions of the manuscript.

Funding: This study was made possible by a NPRP (National Priority Research Program) Award [5-381-3-101] and NPRP Award [7-1648-3-420-4] from the Qatar National Research Fund (a member of The Qatar Foundation). The statements made herein are solely the responsibility of the authors.

Acknowledgments: The publication of this article was funded by the Qatar National Library."

Conflicts of Interest: The authors declare no conflict of interest.

\section{References}

1. Nicolle, S.; Lounis, M.; Willinger, R. Shear properties of brain tissue over a frequency range relevant for automotive impact situations: New experimental results. Stapp Car Crash J. 2004, 48, 239-258. [PubMed]

2. Caine, S.; Hackett, M.J.; Hou, H.; Kumar, S.; Maley, J.; Ivanishvili, Z.; Nichol, H. A novel multi-modal platform to image molecular and elemental alterations in ischemic stroke. Neurobiol. Dis. 2016, 91, 132-142. [CrossRef] [PubMed]

3. Downes, A.; Mouras, R.; Elfick, A. Optical spectroscopy for noninvasive monitoring of stem cell differentiation. J. Biomed. Biotechnol. 2010, 2, 1-10. [CrossRef]

4. Caine, S.; Heraud, P.; Tobin, M.J.; McNaughton, D.; Bernard, C.C. The application of Fourier transform infrared microspectroscopy for the study of diseased central nervous system tissue. Neuroimage 2012, 59, 3624-3640. [CrossRef] [PubMed]

5. Carter, E.A.; Marshall, C.P.; Ali, M.H.; Ganendren, R.; Sorrell, T.C.; Wright, L.; Lee, Y.C.; Chen, C.I.; Lay, P.A. Infrared spectroscopy of microorganisms: characterization, identification, and differentiation. In $A C S$ Symposium Series; Oxford University Press: Oxford, UK, 2007; Volume 963, pp. 64-84.

6. Fabian, H.; Lasch, P.; Boese, M.; Haensch, W. Mid-IR microspectroscopic imaging of breast tumor tissue sections. Biospectroscopy 2002, 67, 354-357. [CrossRef] [PubMed]

7. Rigas, B.; Wong, P.T.T. Human Colon Adenocarcinoma Cell Lines Display Infrared Spectroscopic Features of Malignant Colon Tissues. Cancer Res. 1992, 52, 84-88. [PubMed] 
8. McIntosh, L.M.; Jackson, M.; Mantsch, H.H.; Stranc, M.F.; Pilavdzic, D.; Crowson, A.N. Crowson Infrared spectra of basal cell carcinomas are distinct from non-tumor-bearing skin components. J. Investig. Dermatol. 1999, 112, 951-956. [CrossRef] [PubMed]

9. Gajjar, K.; Heppenstall, L.D.; Pang, W.; Ashton, K.M.; Trevisan, J.; Patel, I.I.; Llabjani, V.; Stringfellow, H.F.; Martin-Hirsch, P.L.; Dawson, T.; et al. Diagnostic segregation of human brain tumours using Fourier-transform infrared and/or Raman spectroscopy coupled with discriminant analysis. Anal. Methods 2013, 5, 89-102. [CrossRef] [PubMed]

10. Choo, L.P.; Wetzel, D.L.; Halliday, W.C.; Jackson, M.; LeVine, S.M.; Mantsch, H.H. In situ characterization of beta-amyloid in Alzheimer's diseased tissue by synchrotron Fourier transform infrared microspectroscopy. Biophys. J. 1996, 71, 1672-1679. [CrossRef]

11. Kneipp, J.; Lasch, P.; Baldauf, E.; Beekes, M.; Naumann, D. Detection of pathological molecular alterations in scrapie-infected hamster brain by Fourier transform infrared (FTIR) spectroscopy. Biochim. Biophys. Acta 2000, 1501, 189-199. [CrossRef]

12. LeVine, S.M.; Wetzel, D.L.B. Analysis of brain tissue by FTIR microspectroscopy. Appl. Spectrosc. Rev. 1993, 28, 385-412. [CrossRef]

13. Matusch, A.; Depboylu, C.; Palm, C.; Wu, B.; Höglinger, G.U.; Schäfer, M.K.H.; Becker, J.S. Cerebral bioimaging of $\mathrm{Cu}, \mathrm{Fe}, \mathrm{Zn}$, and $\mathrm{Mn}$ in the MPTP mouse model of Parkinson's disease using laser ablation inductively coupled plasma mass spectrometry (LA-ICP-MS). J. Am. Soc. Mass Spectrom. 2010, 21, 161-171. [CrossRef] [PubMed]

14. Hare, D.J.; George, J.L.; Grimm, R.; Wilkins, S.; Adlard, P.A.; Cherny, R.A.; Bush, A.I.; Finkelstein, D.I.; Doble, P. Three-dimensional elemental bio-imaging of $\mathrm{Fe}, \mathrm{Zn}, \mathrm{Cu}, \mathrm{Mn}$ and $\mathrm{P}$ in a 6-hydroxydopamine lesioned mouse brain. Metallomics 2010, 2, 745-753. [CrossRef] [PubMed]

15. Hare, D.; Reedy, B.; Grimm, R.; Wilkins, S.; Volitakis, I.; George, J.L.; Chenry, R.A.; Bush, A.I.; Finkelstein, D.I.; Doble, P. Quantitative elemental bio-imaging of $\mathrm{Mn}, \mathrm{Fe}, \mathrm{Cu}$ and $\mathrm{Zn}$ in 6-hydroxydopamine induced Parkinsonism mouse models. Metallomics 2009, 1, 53-58. [CrossRef]

16. Matusch, A.; Becker, J.S. Bio-imaging of metals in a mouse model of Alzheimer's disease by laser ablation inductively coupled plasma mass spectrometry. Biomed. Spectrosc. Imaging 2012, 1, 57-65.

17. Becker, J.S.; Matusch, A.; Becker, J.S.; Wu, B.; Palm, C.; Becker, A.J.; Salber, D. Mass spectrometric imaging (MSI) of metals using advanced BrainMet techniques for biomedical research. Int. J. Mass Spectrom. 2011, 307, 3-15. [CrossRef]

18. Bassan, P.; Kohler, A.; Martens, H.; Lee, J.; Byrne, H.J.; Dumas, P.; Gazi, E.; Brown, M.; Clarke, N.; Gardner, P. Resonant Mie scattering (RMieS) correction of infrared spectra from highly scattering biological samples. Analyst 2010, 135, 268-277. [CrossRef] [PubMed]

19. Kneipp, J.; Lasch, P.; Baldauf, E.; Beekes, M.; Naumann, D. FTIR-microspectroscopy of prion-infected nervous tissue. Biochim. Biophys. Acta 2006, 1758, 948-959.

20. Wang, Q.; Kretlow, A.; Beekes, M.; Naumann, D.; Miller, L. Biomedical Applications of Synchrotron Infrared Microspectroscopy: A Practical Approach. Vib. Spectrosc. 2005, 38, 61-69. [CrossRef]

21. Mendelsohn, R.; Chen, H.C.; Rerek, M.E.; Moore, D.J. Infrared microspectroscopic imaging maps the spatial distribution of exogenous molecules in skin. J. Biomed. Opt. 2003, 8, 185-190. [CrossRef] [PubMed]

22. Leskovjan, A.C.; Lanzirotti, A.; Miller, L.M. Amyloid plaques in PSAPP mice bind less metal than plaques in human Alzheimer's disease. Neuroimage 2009, 47, 1215-1220. [CrossRef] [PubMed]

23. Becker, R.A.; Chambers, J.M.; Wilks, A.R. The New S Language; CRC Press: Boca Raton, FL, USA, 1988.

24. Sanchez, G. Visualizing Dendrograms in R. Available online: http://rpubs.com/gaston/dendrograms (accessed on 21 February 2011).

25. Sadler, T.W. Embryology of Neural Tube Development. Am. J. Med. Gene. Part C 2005, 135C, 2-8. [CrossRef] [PubMed]

26. Srinivasan, G. Vibrational Spectroscopic Imaging for Biomedical Applications; The McGraw-Hill Companies: New York, NY, USA, 2010.

27. Siegel, G.J.; Agranoff, B.W.; Albers, R.W. Basic Neurochemistry: Molecular, Cellular and Medical Aspects, 6th ed.; Lippincott-Raven: Philadelphia, PA, USA, 1999.

28. Nicolson, G.L. The Fluid-Mosaic Model of Membrane Structure: Still relevant to understanding the structure, function and dynamics of biological membranes after more than 40 years. Biochim. Biophys. Acta 2014, 1838, 1451-1466. [CrossRef] [PubMed] 
29. Cakmak, G.; Miller, L.M.; Zorlu, F.; Severcan, F. Amifostine, a radioprotectant agent, protects rat brain tissue lipids against ionizing radiation induced damage: An FTIR microspectroscopic imaging study. Arch. Biochem. Biophys. 2012, 520, 67-73. [CrossRef] [PubMed]

30. Bazinet, R.P.; Sophie, L. Polyunsaturated fatty acids and their metabolites in brain function and disease. Nat. Rev. Neurosci. 2014, 15, 771-785.

31. Lars, S. Distribution and fatty acid composition of phosphoglycerides in normal human brain. J. Lipid Res. 1968, 9, 570-579.

32. O'Brien, J.S.; Sampson, E.L. Fatty acid and fatty aldehyde composition of the major brain lipids in normal human gray matter, white matter, and myelin. J. Lipid Res. 1965, 6, 545-551. [PubMed]

33. Kandel, E.R.; Schwartz, J.H.; Jessell, T.M. Principles of Neural Science, 4th ed.; McGraw-Hill, Health Professions Division: New York, NY, USA, 2000.

34. Hanna, R.; Doudna, J.A. Metal ions in ribozyme folding and catalysis. Curr. Opin. Chem. Biol. 2000, 4, 166-170. [CrossRef]

(C) 2018 by the authors. Licensee MDPI, Basel, Switzerland. This article is an open access article distributed under the terms and conditions of the Creative Commons Attribution (CC BY) license (http://creativecommons.org/licenses/by/4.0/). 